\title{
Out of the blue: Vermeer's use of ultramarine in Girl with a Pearl Earring
}

\author{
Annelies van Loon ${ }^{1,2^{*}} \mathbb{0}$, Alessa A. Gambardella², Victor Gonzalez ${ }^{2,3}$, Marine Cotte ${ }^{4,5}$, Wout De Nolf ${ }^{4}$, \\ Katrien Keune ${ }^{2,6}$, Emilien Leonhardt ${ }^{7}$, Suzan de Groot ${ }^{8}$, Art Ness Proaño Gaibor ${ }^{8}$ and Abbie Vandivere
}

\begin{abstract}
Johannes Vermeer (1632-1675) is known for his brilliant blue colours, and his frequent use of the costly natural ultramarine. This paper reveals new findings about ultramarine in the headscarf of Girl with a Pearl Earring (c. 1665, Mauritshuis). The painting was examined using a range of micro- and macroscale techniques as part of the Girl in the Spotlight research project (2018). Analysis of micro-samples mounted as cross-sections using SEM-EDX and FTIR-ATR showed that Vermeer used high-quality ultramarine in the blue headscarf, based on the relative abundance of bright blue particles of lazurite. Analysis with synchrotron sulphur K-edge XANES suggested that the ultramarine pigment was prepared - at least in part-from a heat-treated lapis lazuli rock. The entire painting was imaged using MS-IRR, MA-XRF, RIS, and digital microscopy to reveal the distribution of materials of the headscarf, and to give more insight into Vermeer's painting process. The shadow part of the headscarf has a remarkably patchy appearance, due to paint degradation that is probably related to the large amounts of chalk Vermeer mixed in the ultramarine paint in this area. The question was raised as to whether extra chalk was added deliberately to the paint to adjust the handling properties or opacity, or whether the chalk was the substrate of a-now faded —yellow lake. Schematic paint reconstructions were made to investigate the effect of the addition of chalk or yellow lake on the paint properties. The analyses and reconstructions led to the hypothesis that the blue headscarf originally contained a wider range of different blue colour shades: an opaque light blue for the left (lit) zone, a slightly brighter opaque blue for the middle zone, and a deep dark blue-green glaze with alternating blue-green glazing brushstrokes for the shadow zone-now largely compromised by paint degradation.
\end{abstract}

Keywords: Painting technique 17th century, Johannes Vermeer, Ultramarine, Organic lakes, MA-XRF, Reflectance imaging spectroscopy, $\mu$-XANES, Paint reconstructions

\section{Introduction}

Ultramarine was by far the most expensive blue pigment available in the seventeenth century. Dutch high-life genre painters, including Vermeer, were especially fond of ultramarine, and its distinctive intense blue colour [13]. Its presence may even have enhanced the value of a painting for collectors [3]. They not only used it for blues, but also in mixtures: for instance, mixed with yellow lake or lead-tin yellow to make green, or in small quantities

\footnotetext{
*Correspondence: a.van.loon@rijksmuseum.nl

${ }^{1}$ Conservation Department, Mauritshuis, Plein 29, 2511 CS The Hague, The Netherlands

Full list of author information is available at the end of the article
}

with white paint to make it appear even whiter [3]. In Vermeer's Girl in Blue Reading a Letter (c. 1663-1664, Rijksmuseum), ultramarine was incorporated throughout: in the blue dress, tablecloth, upholstery of the chairs, while small additions also give the white rear wall its bluish tinge [4]. More unusually, Vermeer combined ultramarine with green earth in the dress of Young Woman Seated at a Virginal (c. 1670-1672, National Gallery London) to produce a distinctive blue-green colour [5].

In Girl with a Pearl Earring (c. 1665, Mauritshuis) (Fig. 1a), Vermeer used ultramarine extensively in the Girl's headscarf, and mixed with other pigments in the shadows of her yellow jacket [6-8]. A trace amount of ultramarine was also found in the pink flesh paint. The

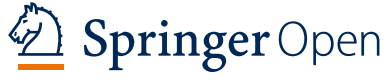

(c) The Author(s) 2020. This article is licensed under a Creative Commons Attribution 4.0 International License, which permits use, sharing adaptation, distribution and reproduction in any medium or format, as long as you give appropriate credit to the original author(s) and the source, provide a link to the Creative Commons licence, and indicate if changes were made. The images or other third party material in this article are included in the article's Creative Commons licence, unless indicated otherwise in a credit line to the material. If material is not included in the article's Creative Commons licence and your intended use is not permitted by statutory regulation or exceeds the permitted use, you will need to obtain permission directly from the copyright holder. To view a copy of this licence, visit http://creativeco mmons.org/licenses/by/4.0/. The Creative Commons Public Domain Dedication waiver (http://creativecommons.org/publicdomain/ zero/1.0/) applies to the data made available in this article, unless otherwise stated in a credit line to the data. 


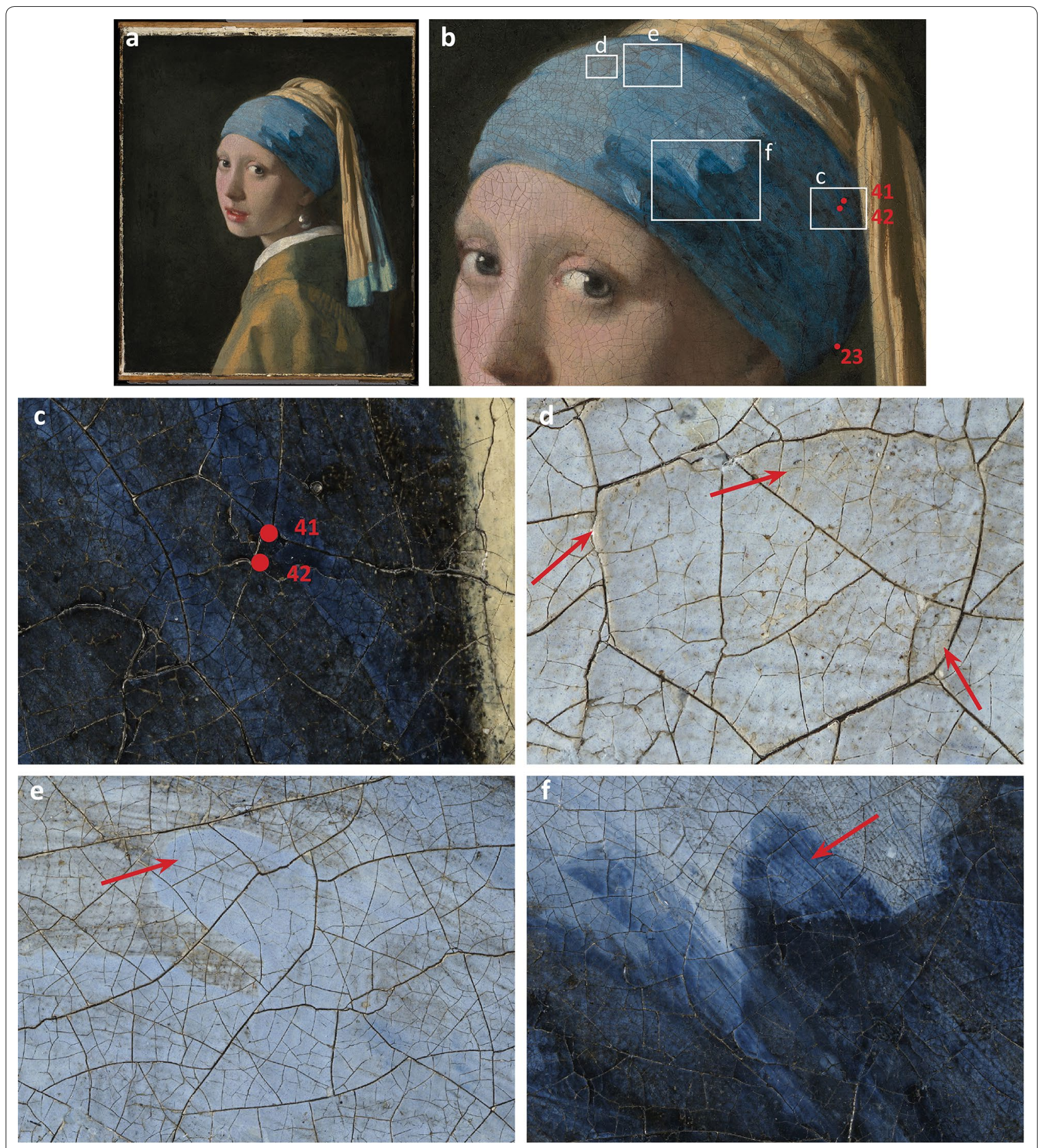

Fig. 1 a Johannes Vermeer, Girl with a Pearl Earring, c. 1665, oil on canvas, $44.5 \times 39$ cm, Mauritshuis, The Hague (inv. nr. 670). Photo credits: René Gerritsen Art \& Research Photography. b Visible light image of the blue headscarf, showing the sample locations (red dots) and microphotograph areas shown in $\mathbf{c}-\mathbf{f}$ (white boxes). c Detail of right (shadow) side. $\mathbf{d}$ Detail showing the grey ground beneath the light blue highlight. e The light blue of the middle tone applied thickly, using curved brushstrokes to create 'undulating' folds between the highlight and midtone. f Wide brushstroke of intensely-coloured blue glaze that overlaps the lighter blue layer of the middle tone 
other blue pigment used in the Girl was indigo, which was mixed with a yellow organic lake (weld on a chalk substrate) to create a green glaze as a top layer in the background $[6,9]$.

Vermeer painted the Girl as a tronie: a character study. The painting may have been one of "two tronies painted in the Turkish fashion" mentioned in the 1679(?) inventory of Vermeer's belongings after his death (twee tronijnen geschildert op sijn Turx) [10]. The exotic "Turkish" fashion is suggested by the Girl's headscarf, which is probably made of two pieces of fabric: a blue scarf wrapped around her head, a yellow one that is piled atop her head with 'tails' that fall down her back. In this paper, the word 'headscarf' will refer to the blue part of the headdress, unless otherwise specified.

This paper focuses on the headscarf of the Girl, specifically: the quality and production of the blue ultramarine pigment, other materials used in the headscarf, the stratigraphy and painting process, and how its appearance has changed over time. Girl with a Pearl Earring was last examined in the 1990s, but only one sample from the edge of the headscarf was available (and not published) [6]. In 2018, the painting was re-examined within The Girl in the Spotlight research project [11]. All of the research questions that guided the project were relevant to the investigation of the headscarf: What steps did Vermeer take (in the painting process)? What can we find out about layers beneath the surface? Which materials did Vermeer use and where did they come from? Which techniques did Vermeer use to create subtle optical effects? What did (different areas of) the painting look like originally, and how have they changed?

In 2018, two new micro-samples were collected from the headscarf, embedded as paint cross-sections, and analysed using: light microscopy (LM), scanning electron microscopy-energy dispersive X-ray analysis (SEMEDX), and micro Fourier transform infrared-attenuated total reflectance spectroscopy ( $\mu$-FTIR-ATR). This combination of techniques was used to reveal the layer stratigraphy and the materials used in the headscarf, the quality of the ultramarine pigment, and associated reaction products. Because EDX only provides elemental information, complementing this technique with $\mu$-FTIRATR reveals molecular information about the paint components.

Sulphur K-edge X-ray absorption near-edge structure spectroscopy in microbeam mode ( $\mu$-XANES) was performed to analyse sulphur species of lazurite particles. Use of a sub-micrometric beam is essential for the location of lazurite particles in the samples, since sulphur can be present in different species (e.g. other artists' pigments). This technique can provide more information about the preparation of ultramarine pigment-specifically, whether the lazurite had been extracted from heat-treated lapis lazuli rock-as recently described in Gambardella et al. [12].

As part of the recent analysis, a large amount of chalk was identified in the ultramarine paint of the shadow areas of the headscarf. This suggests a deliberate addition, or the use of-a now faded-organic lake pigment. To support this, the paper compares the results of the analysis of organic lakes in the headscarf with the lake(s) detected in the background and jacket of Girl with a Pearl Earring $[8,9]$. The red and/or yellow dyestuffs in small paint fragments were analysed using ultra-high performance liquid chromatography with a photodiode array, attached to a fluorescence detector (UHPLCPDA-FLR). Schematic paint reconstructions were made to investigate the effect of the addition of chalk or yellow lake on the working and visual properties of an ultramarine paint.

The Girl in the Spotlight research team also imaged the entire painting using complementary non-invasive imaging techniques. To investigate the headscarf, the most informative techniques were: multispectral infrared reflectography (MS-IRR, 1100-2500 nm), macroscopic $\mathrm{X}$-ray fluorescence scanning (MA-XRF), visible and near-infrared reflectance imaging spectroscopy (RIS), and 3D digital microscopy. MS-IRR was able to visualise the black carbon-containing underlayers. The extension towards longer wavelengths allows penetration beneath lead white-containing surface paint layers [7]. MA-XRF mapped the distribution of chemical elements in the paint layers of the headscarf, from which pigments could be inferred [13]. It is capable of detecting the presence of lead ( $\mathrm{Pb}-\mathrm{M}$ and $\mathrm{Pb}-\mathrm{L}$ ) indicative of lead white in both surface and underlayers. Calcium $(\mathrm{Ca}-\mathrm{K})$ and potassium $(\mathrm{K}-\mathrm{K})$ can be associated with both ultramarine and (substrates of) organic lake pigments [8, 14-17]. MA-XRF is not, however, the most suitable technique to identify and map ultramarine. Apart from calcium and potassium, the XRF emission of the other elements characteristic of ultramarine $(\mathrm{Na}, \mathrm{Al}, \mathrm{Si}, \mathrm{S})$ are easily absorbed-by paint materials, the air, the detector window-and are hardly detectable with a scanning setup. Instead, the RIS falsecolour images provided valuable information about the distribution of ultramarine in the headscarf [8]. RIS could not detect and image chalk, since the characteristic feature of chalk-a carbonate ion asymmetric stretching at approx. $2340 \mathrm{~nm}$-was outside the spectral range of the cameras (operated from 400 to $1000 \mathrm{~nm}$, and from 967 to $1680 \mathrm{~nm})[8,18]$. 3D digital microscopy imaged the entire painting at $35 \times$ magnification, resulting in c. 9000 tiles that were stitched together, providing a visual image of $4.4 \mu \mathrm{m} /$ pixel (almost $6000 \mathrm{dpi}$ ). The combination of noninvasive imaging, microscopic examination of the paint 
surface, and analysis of paint micro-samples revealed the steps in the painting process of the headscarf. The combination of these methods also helped to explain a deterioration phenomenon: a whitish surface on the shadow side of the headscarf. The relation of this surface phenomenon to the presence of chalk in the shadow of the headscarf (as mentioned above) was also investigated. This paper concludes by discussing how the headscarf might have changed in appearance over time, due to the fading of yellow lake.

\section{Preparation methods of ultramarine}

Ultramarine is composed of the blue mineral lazurite, which is the main component of the semi-precious stone lapis lazuli, and is a complex sulphur-containing sodium aluminium silicate with the formula $(\mathrm{Na}, \mathrm{Ca})_{8}\left(\mathrm{AlSiO}_{4}\right)_{6}\left(\mathrm{SO}_{4}, \mathrm{~S}, \mathrm{Cl}\right)_{2}$ [19]. Its blue colour derives from the sulphur-containing radical anions inside the aluminosilicate framework. The mineral is typically associated with calcite, pyrite, and (colourless) silicate minerals [14].

The lapis lazuli stone was mined in Afghanistan in the seventeenth century, then imported through Venice into Europe. It was prepared as a pigment following a method that was in use from the fourteenth century onwards, also called the pastello treatment [19]. After grinding the stone into a fine powder, it was incorporated into a mixture of wax, resin and linseed oil. This mass, usually wrapped in a cloth, was left to sit for several weeks, after which it was kneaded in rain water or a diluted solution of lye. The blue particles dispersed into the liquid, while the impurities remained in the mass. This process was usually repeated several times, with each successive extraction generating a lower quality pigment. The final extraction-consisting largely of colourless material, and a few small blue particles-was known as ultramarine ash.

In addition to describing steps to isolate lazurite from accessory minerals in lapis lazuli, historical recipes in some instances also instruct the heating of lapis lazuli rock until 'red hot' prior to grinding $[14,20]$. As a focus of a recent publication by Gambardella et al. [12], it was observed that heat-treatment of naturally-sourced lapis lazuli not only produces a darker blue hue of lazurite, but also makes the rock easier to grind to a powder. Complementary to the former observation, sulphur K-edge XANES - sensitive to the coordination chemistry and oxidation state of the sulphur species present in lazurite-revealed that heat-treatment also leads to an increase in the relative content of sulphur radical species, those responsible for the blue hue, in the extracted lazurite pigment [12]. Specifically, some spectral patterns of lazurite from lapis lazuli heat-treated at 750 and $600{ }^{\circ} \mathrm{C}$ were found to be unique, thereby providing a characteristic marker for pigment deriving from heat-treated lapis lazuli rock in historical paintings [12].

\section{Experimental methods \\ Micro-sample analysis \\ Paint micro-samples and sample preparation}

During the restoration treatment of Girl with a Pearl Earring in 1994, microscopic samples were collected from the painting [6]. As opportunities to sample alongside damages were limited, the only sample that included the blue headscarf was sample 23: collected from the lower right edge of the blue headscarf, where it meets the dark background (Fig. 1b) [6, 11]. As such, it was unclear whether this sample was representative of the buildup of other parts of headscarf, or whether its composition or stratigraphy differed because it was taken along a contour. Sample 23 was mounted as cross-section by embedding it in Poly-pol PS230: a two-component polyester mounting resin (Poly-Service Amsterdam, the Netherlands). As part of the 2018 Girl in the Spotlight project, sample 23 was re-examined using light microscopy (LM) and SEM-EDX. Analysis of the organic dyestuff using UHPLC-PDA-FLR was carried out on tiny unmounted fragments preserved from the analyses carried out in the 1990s: two fragments from sample 23, and one from sample 14a from the jacket (dislodged sample, precise original location unknown, probably from the shadow of the Girl's jacket).

In 2018, new microscopic paint samples were collected from two blue tones next to each other on the right (shadow) side of the headscarf in order to analyse and compare their stratigraphies and materials: a bright blue brushstroke (sample 41), and a dark blue shadow tone (sample 42). They were embedded in Technovit 2000 LC mounting resin-a one-component methacrylate that cures under visible blue light (Heraeus Kulzer $\mathrm{GmbH}$, Germany)-and polished using a sample holder and Micromesh sheets up to grade 12,000 (Micro-Surface Finishing Products Inc., Wilton, Iowa, USA) [21]. The cross-sections were examined using: LM, SEM-EDX, $\mu$-FTIR-ATR, and synchrotron $\mu$-XRF/ $\mu$-XANES. More information about the samples can be found in Table 1. Sample locations are illustrated in Fig. 1b, c.

\section{Light microscopy (LM)}

A Zeiss Axio Imager.A2m microscope equipped with a Zeiss AxioCam MRc5 digital camera was used to (re-) examine the polished cross-sections 23, 41 and 42, and to capture images at spatial resolutions of $0.27 \mu \mathrm{m} /$ pixel $(200 \times)$ and $0.11 \mu \mathrm{m} /$ pixel $(500 x)$ in bright field, dark field and ultraviolet (UV-A). Luminescence images were obtained with a LED $365 \mathrm{~nm}$ light source, and a filter 
Table 1 Micro-samples of ultramarine-containing paints in Girl with a Pearl Earring

\begin{tabular}{|c|c|c|}
\hline Sample number/type/location & Analyses & Stratigraphy and pigments \\
\hline $\begin{array}{l}23 \text { Cross-section } \\
\text { Lower right edge of the blue headscarf }\end{array}$ & $\begin{array}{l}\text { Sampled and analysed } 1994[6] \text { : } \\
\text { LM } \\
\text { SEM-EDX } \\
\text { Photographed } 2008 \\
\text { Analysed 2018: } \\
\quad \text { LM } \\
\text { SEM-EDX }\end{array}$ & $\begin{array}{l}\text { Blue paint layer: ultramarine, chalk, (possibly very tiny } \\
\text { amount of) lead white, indigo (from background glaze } \\
\text { [9]) } \\
\text { Black underlayer: mainly charcoal black }\end{array}$ \\
\hline $\begin{array}{l}23 \text { Unmounted fragment } \\
\text { Lower right edge of the blue headscarf }\end{array}$ & $\begin{array}{l}\text { Sampled } 1994 \\
\text { Analysed 2018: } \\
\quad \text { UHPLC-PDA-FLR }\end{array}$ & $\begin{array}{l}\text { Organic components: indigo, unidentified yellow compo- } \\
\text { nents }\end{array}$ \\
\hline $\begin{array}{l}41 \text { Cross-section } \\
\text { Dark blue in shadow on right of headscarf }\end{array}$ & $\begin{array}{l}\text { Sampled and analysed 2018: } \\
\text { LM } \\
\text { SEM-EDX } \\
\text { H-FTIR-ATR } \\
\text { Synchrotron } \mu \text {-XANES/ } \mu-X R F\end{array}$ & $\begin{array}{l}\text { Thick blue paint layer (up to } 70 \mu \mathrm{m} \text { ): ultramarine, chalk, lead } \\
\text { white, red lake, gypsum } \\
\text { Black underlayer (incomplete): mainly charcoal black }\end{array}$ \\
\hline $\begin{array}{l}42 \text { Cross-section } \\
\text { Bright blue in shadow on right of headscarf }\end{array}$ & $\begin{array}{l}\text { Sampled and analysed } 2018 \text { : } \\
\text { LM } \\
\text { SEM-EDX } \\
\mu \text {-FTIR-ATR } \\
\text { Synchrotron } \mu \text {-XANES/ } \mu-\text { XRF }\end{array}$ & $\begin{array}{l}\text { Thin blue paint layer (c. } 10 \mu \mathrm{m} \text { thick): ultramarine, chalk, lead } \\
\text { white, red lake, gypsum } \\
\text { Thin black underlayer (c. } 10 \mu \mathrm{m} \text { thick): charcoal black, chalk, } \\
\text { gypsum, a few aluminium-containing particles, palmierite } \\
\text { (degradation product) } \\
\text { Ground (up to } 50 \mu \mathrm{m} \text { thick): chalk, lead white, earth pig- } \\
\text { ments, fine carbon black }\end{array}$ \\
\hline $\begin{array}{l}14 a \text { Dislodged unmounted fragment } \\
\text { Precise original location unknown: } \\
\text { probably from the shadow of the Girl's } \\
\text { clothing }\end{array}$ & $\begin{array}{l}\text { Sampled } 1994 \\
\text { Analysed 2018: } \\
\text { UHPLC-PDA-FLR (to compare } \\
\text { organic components with those found in } \\
\text { the headscarf) }\end{array}$ & Organic components: American cochineal \\
\hline
\end{tabular}

cube composed of a $365 \mathrm{~nm}$ excitation filter (EX G 365), a beamsplitter at $395 \mathrm{~nm}$ (BS FT 395), and an emission long-pass filter at $420 \mathrm{~nm}$ (EM LP 420).

\section{Scanning electron microscopy-energy dispersive $X$-ray analysis (SEM-EDX)}

SEM backscattered-electron images of cross-sections 23, 41 and 42 (uncoated) were acquired with an FEI NovaNano SEM 450 variable pressure electron microscope operated at low vacuum $(70 \mathrm{~Pa})$, and an accelerating voltage of $20 \mathrm{kV}$. The SEM was equipped with a ThermoFisher NSS EDX system to yield elemental composition of the pigments within the layers. EDX mapping was done using the same instrument, but operating at high vacuum. The samples were gold-coated prior to EDX mapping to improve surface conductivity. All the samples were mapped using spectral imaging at $1200 \times$ magnification. Each map consists of $512 \times 340$ pixels and the collection time was typically $30 \mathrm{~min}$.

\section{Micro Fourier transform infrared-attenuated total reflectance spectroscopy ( $\mu$-FTIR-ATR)}

FTIR spectral data of cross-sections 41 and 42 were collected on a Perkin Elmer Spectrum 100 FTIR spectrometer combined with a Spectrum Spotlight 400 FTIR microscope equipped with a $16 \times 1$ pixel linear mercury cadmium telluride (MCT) array detector. A Perkin Elmer ATR imaging accessory consisting of a germanium crystal was used for ATR imaging. The spectral resolution was $16 \mathrm{~cm}^{-1}$. The mapping area was $300 \times 400 \mu^{2}$ in size, with a spatial resolution of $6.25 \mu \mathrm{m} /$ pixel.

\section{Synchrotron: Micro sulphur K-edge X-ray absorption near-edge structure spectroscopy ( $\mu$-XANES) with macro $X$-ray fluorescence spectroscopy ( $\mu$-XRF)}

Cross-sections 41 and 42 were analysed using $\mu$-XANES with an attenuated microbeam (spot size of $0.6 \times 1.0 \mu \mathrm{m}^{2}$, flux of $4.3 \times 10^{8}$ photons $\mathrm{s}^{-1}$, attenuated using a $6 \mu \mathrm{m}$ aluminium filter to mitigate radiation damage) in XRF mode. The analysis was done at the European Synchrotron Radiation Facility (ESRF, Grenoble, France) using beam line ID21 following the same protocol, instrumental settings, and data processing steps as Gambardella et al. [12] Points-of-interest in each sample were chosen based on the distribution of $\mathrm{Al}, \mathrm{Si}$, and $\mathrm{S}$ in $\mu$-XRF maps. To retain sufficient signal-to-noise with the attenuation, several spectra from 
different locations per each particle were acquired and then averaged [12].

\section{Ultra-high performance liquid chromatography with a photo diode array, attached to a fluorescence detector (UHPLC-PDA-FLR)}

Samples 14a and 23 (unmounted fragments) were analysed by means of ultra-high-performance liquid chromatography (UHPLC) with a photo diode array (PDA, $\lambda=200-800 \mathrm{~nm})$, attached to a fluorescence detector (FLR, $\lambda_{\text {em }}=510 \mathrm{~nm}, \lambda_{\text {ex }}=580 \mathrm{~nm}$ ).

The samples were photographed with a digital microscope and then transferred to glass micro-vials. Extraction was carried out with a $15 \mu \mathrm{L}$ solution of hydrochloric acid (36\% technical-Acros), water (Millipore) and methanol (LC-MS grade-Honeywell) in 2:1:1 ratio, respectively. The extraction was vortexed for $8 \mathrm{~s}$ and heated in a water bath at $100{ }^{\circ} \mathrm{C}$ for $10 \mathrm{~min}$. The sample was then evaporated under a gentle nitrogen flow $(30 \mathrm{~min})$. When dry, the sample was solubilised with $16 \mu \mathrm{L}$ of dimethyl sulphoxide (DMSO-Sigma Aldrich), the micro-vial was briefly vortexed and then centrifuged at $90 \mathrm{G}$ for $5 \mathrm{~min}$.

The chromatography apparatus used was a Waters ${ }^{\circledR}$ ACQUITY UPLC H-Class System. The column was a $\mathrm{C} 18,15 \mathrm{~cm} \mathrm{BEH}$ (ethylene bridged hybrid) column with a pre-filter, used to separate the colourants with a solvent gradient of: (a) 10\% methanol in water, (b) 100\% methanol and (c) $1 \%$ formic acid. $5 \mu \mathrm{L}$ of the extracted samples were injected into the column with an auto sampler [22].

\section{Non-invasive chemical imaging \\ Multispectral infrared reflectography (MS-IRR, 1100- $2500 \mathrm{~nm}$ )}

Multispectral infrared reflectography in the 1100$2500 \mathrm{~nm}$ range was done with a near infrared optimised high spatial resolution infrared camera outfitted with broadband interference bandpass filters (J: 1100$1400 \mathrm{~nm}, \mathrm{H}: 1500-1800 \mathrm{~nm}$, and $1900-2500 \mathrm{~nm})$. The camera consisted of a $50 \mathrm{~mm}$ EFL F/D 2.3 lens (Stingray, $\mathrm{NH}$ ) optimised for the spectral range from 1000 to $2600 \mathrm{~nm}$ and a high definition infrared camera (model 912, IRCameras, CA) having an indium antimonide $(\mathrm{InSb})$ detector array of $1280 \times 1024$ pixels. The spatial sampling was $50 \mu \mathrm{m} /$ pixel at the painting. The resulting images were spatially mosaicked by registering with a visible light image of the painting using a previously published algorithm [23].

\section{Macroscopic X-ray fluorescence (MA-XRF) scanning}

MA-XRF maps of the entire painting were collected in two scan sessions (total time $46 \mathrm{~h}$ ) using the Bruker M6 Jetstream [24]. The instrument consists of a measuring head equipped with a $30 \mathrm{~W}$ rhodium-target microfocus
X-ray tube, a polycapillary lens, and a $60 \mathrm{~mm}^{2}$ XFlash silicon drift detector (SDD) with a beryllium window (energy resolution $<145 \mathrm{eV}$ at $\mathrm{Mn}-\mathrm{K}_{\alpha}$ ). By slowly moving the measuring head on the $X Y$-motorised stage, the painting was scanned pixel by pixel, line by line. By recording the emitted XRF radiation, the chemical elements present in the paint (associated with specific pigments) can be identified. With the Bruker M6 Jetstream, only elements heavier than silicon can be detected. The entire painting was scanned at $50 \mathrm{kV}$ and a current of 600 $\mu \mathrm{A}$, with a $400 \mu \mathrm{m}$ step size, and a dwell time of $125 \mathrm{~ms}$. The distance between the scanning head and the paint surface was set at approximately $1 \mathrm{~cm}$, corresponding to an X-ray spot size of c. $250 \mu \mathrm{m}$. All data were collected with the Bruker M6 Jetstream software package. The acquired data cubes were then exported as raw files and processed and stitched using PyMca and Datamuncher software to produce elemental distribution maps [25].

\section{Reflectance imaging spectroscopy (RIS): visible-to-near-infrared (VNIR: $400-1000 \mathrm{~nm}$ ) and shortwave infrared (SWIR: 967-1680 nm)}

Hyperspectral reflectance image cubes of the entire painting were collected with optimised whiskbroom linescanning imaging spectrometers (Surface Optics Corporation, USA) that have been previously described [26]. The VNIR imaging spectrometer (V10E Specim Corp., Finland) was coupled to a backside illuminated Si CCD array (ProEM1024, Princeton Instruments, USA) operating from 400 to $1000 \mathrm{~nm}$ with $2.5 \mathrm{~nm}$ sampling, at a light level of 1200-1500 lx and integration time of $150 \mathrm{~ms}$ per line. The SWIR imaging spectrometer was coupled to an InGaAs array (SUI 640HSX-1.7RT, Sensors Unlimited, USA) operating from 967 to $1680 \mathrm{~nm}$ with $3.4 \mathrm{~nm}$ sampling, $700 \mathrm{~lx}$, and an integration time of $33 \mathrm{~ms}$ per line. The image cubes were dark-corrected, flat-fielded, and calibrated to apparent reflectance using diffuse reflectance standards (Labsphere Inc, USA). The calibrated image cubes were spatially registered using a point-based algorithm [23], and the resulting spatial sampling at the painting was $0.17 \mathrm{~mm} /$ pixel for both cameras.

\section{Surface examination and digital microscopy Stereomicroscopy}

The painting was examined at up to $40 \times$ magnification using a Zeiss Universal S2 stereomicroscope to characterise the painting sequence.

\section{High-resolution 3D digital microscopy}

The painting was examined using the Hirox RH-2000 3D digital microscope on a motorised 'bridge' stand with a $500 \times 500 \mathrm{~mm}$ automatic motorised $X Y$ stage $(200 \mathrm{~nm}$ steps). The 'bridge' stand was made specifically for the 
(See figure on next page.)

Fig. 2 Paint cross-section from a bright blue tone from right (shadow) side of blue headscarf (sample 41). a Sample location, b LM image, dark field, c UV-induced fluorescence. d Corresponding SEM backscattered-electron image. The sample was further polished for the data shown in e-I, o-r, and therefore do not correspond exactly to $\mathbf{a}-\mathbf{d}$. The EDX maps were done last. e detail SEM backscattered-electron image, EDX maps of: $\mathbf{f}$ sodium, $\mathbf{g}$ aluminium, $\mathbf{h}$ silicon, $\mathbf{i}$ sulphur, $\mathbf{j}$ potassium, $\mathbf{k}$ calcium, I magnesium, and EDX spectra of: $\mathbf{m}$ lazurite particle, $\mathbf{n}$ chalk particle. $\mu$-FTIR-ATR analysis: o FTIR-ATR spectra belonging to lazurite, chalk, gypsum, $\mathbf{p}$ distribution map of the $978 \mathrm{~cm}^{-1}$ band characteristic of lazurite, $\mathbf{q} 870 \mathrm{~cm}^{-1}$ band characteristic of chalk, $\mathbf{r} 1110 \mathrm{~cm}^{-1}$ band characteristic of gypsum

Girl in the Spotlight project to accommodate the painting, which was placed horizontally. The microscope zoom lens MXB-5000REZ was mounted on the Hirox FB-E $Z$-axis block with $30 \mathrm{~mm}$ motorised movement $(50 \mathrm{~nm}$ steps). It can achieve spatial sampling from $4.4 \mu \mathrm{m} /$ pixel (35x) down to $0.03 \mu \mathrm{m} /$ pixel $(5000 \times)$; for the images in this paper, the former was used. The illumination used was mixed: raking light (100\% light intensity) and ring light/dark field ( $10 \%$ light intensity). At $35 \times$ magnification $(4.4 \mu \mathrm{m} /$ pixel), the tile size is $8.5 \times 5.28 \mathrm{~mm}$.

The complete painting was automatically scanned at a sampling resolution of $4.4 \mu \mathrm{m} /$ pixel with a $30 \%$ overlap: the microscope acquired a series of images in the $Z$-axis, capturing each focus layer and then combining them in one single all-in-focus image (also known as $Z$-stacked or extended depth of field). The microscope then moved in the $X$ and/or $Y$ direction to the next tile, and the process automatically started again, so that a total of 9100 $Z$-stacked images were acquired in approximately $14 \mathrm{~h}$. For each tile, a $Z$-stacked image as well as a TDR file (Hirox 3D file format) were created, which included true colours and altitude, so that the $X Y Z$ coordinates are registered for each pixel.

The Hirox RH-2000 main unit software (which was modified specifically for this project) was used to calibrate and display a live image, then to create full auto $Z$-stacked 3D data and to program a fully automatic $X Y Z$ acquisition with selectable overlap (offline tiling without any pixel size limit in the full scan). Stitching the $4.4 \mu \mathrm{m} /$ pixel resolution images created an all-in-focus stitched image of the full painting at approximately 10 billion pixel resolution.

\section{Painted reconstructions}

For the materials and methods used to make the painted reconstruction, see Additional file 1.

\section{Results and discussion}

Micro-sample analysis of the blue headscarf

Paint samples from shadow areas: stratigraphy and material composition

The study of paint cross-sections helped to determine the layer stratigraphy of the blue headscarf, and to characterise the ultramarine pigment and other materials that Vermeer used to paint it. Two sample locations were carefully selected from the right (shadow) side of the blue headscarf based on the preliminary macro-imaging results: a bright blue brushstroke that has some reliefapplied in the final stages of the painting process-and a dark blue tone from an adjacent area, applied thinly (Fig. 1b, c). Both areas exhibited a superficial whitish surface haze, but the haze was more noticeable in the darkest blue. Characterisation of both samples was achieved using LM, SEM-EDX, and $\mu$-FTIR-ATR (Table 1).

In the cross-section from the bright blue brushstroke (sample 41), LM and SEM-EDX identified a thick (up to $70 \mu \mathrm{m}$ ) layer of blue paint (Fig. 2, layer 3) applied on top of a black underlayer (Fig. 2b-d, layer 2). The grey ground, identified in other cross-sections [7] and sample 42 (below), is missing in this sample. The underlayer contains predominantly black particles. The splintery shape of the particles, together with the detection of $C$ using SEM-EDX, suggests a charcoal black. In the blue layer, bright blue particles and some fine white particles in a translucent matrix are observed in the LM image (Fig. 2b-d, layer 3). Using SEM-EDX, Na, Al, Si, and $\mathrm{S}$ were co-detected (Fig. 2f, g, h, i, m) in the particles observed as bright blue in the LM image (Fig. 2b, c): this indicates the presence of lazurite, the blue mineral of ultramarine pigment. Surrounding these particles, an abundance of Ca was also detected (Fig. 2k, n) with EDX. Only in very few spots, $\mathrm{Ca}$ is co-localised with $\mathrm{S}$, suggesting its main presence as chalk $\left(\mathrm{CaCO}_{3}\right)$, with some particles as calcium sulphate. The proportion of lazurite to chalk is estimated to be about 50:50, based on the EDX maps from $\mathrm{Na}, \mathrm{Al}, \mathrm{Si}$ and $\mathrm{Ca}$ (Fig. 2f, g, h, k). Further in the surrounding matrix, $\mathrm{Pb}$ was detected in the fine white particles observed in the LM image, suggesting the presence of lead white pigment. Of the remaining particles, co-locations of $\mathrm{Si}, \mathrm{Al}$, and $\mathrm{K}$ (without detection of $\mathrm{S}$ ) as well as $\mathrm{Si}, \mathrm{Ca}$, and $\mathrm{Mg}$ (in one particle) were detected with EDX. These elements suggest the presence of accessory minerals related to lazurite in lapis lazuli: respectively, a feldspar mineral $\left(\mathrm{KAlSi}_{3} \mathrm{O}_{8}\right)$ and diopside $\left(\mathrm{MgCaSi}_{2} \mathrm{O}_{6}\right)$. The presence of only a few particles of accessory minerals relative to the large number of lazurite particles implies that a high-quality ultramarine was used.

In agreement with the SEM-EDX results, $\mu$-FTIR-ATR analysis of sample 41 identified lazurite and chalk in the blue paint layer (Fig. 2o-q). The distribution of lazurite 

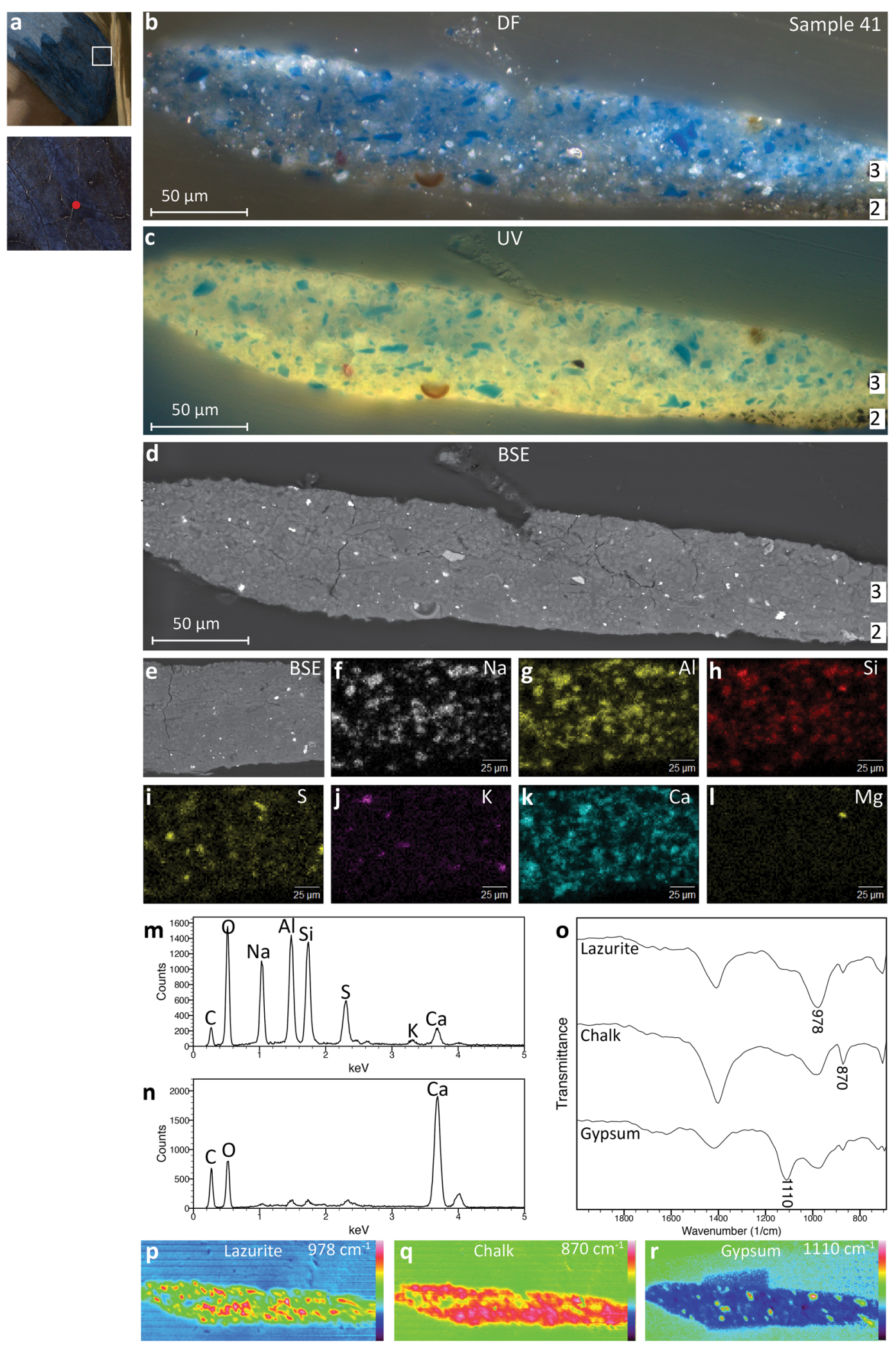
is mapped using a characteristic absorption band at c. $978 \mathrm{~cm}^{-1}$ from silicate (Si-O stretch) (Fig. 2o, p) [27]; chalk has a sharp absorption band at c. $870 \mathrm{~cm}^{-1}$ from carbonate ( $\mathrm{C}-\mathrm{O}$ out-of-plane bending), which was used to map its distribution (Fig. 2o, q) [27]. In addition to lazurite and chalk, $\mu$-FTIR-ATR detected some particles of gypsum $\left(\mathrm{CaSO}_{4} \cdot 2 \mathrm{H}_{2} \mathrm{O}\right)$ distributed throughout the blue layer. Figure $2 \mathrm{r}$ shows the distribution of the strong sulphate band (S-O stretch) at c. $1110 \mathrm{~cm}^{-1}$, characteristic of gypsum (Fig. 2o, r) [27].

The cross-section from the dark blue shadow (sample 42) shows a thick layer of medium-grey ground (Fig. 3b$\mathrm{d}$, layer 1 , up to $50 \mu \mathrm{m}$ thick), followed by a thin black underlayer (Fig. 3b-d, layer 2, c. $10 \mu \mathrm{m}$ thick), and a thin blue surface paint layer (Fig. 3b-d, layer 3, c. $10 \mu \mathrm{m}$ thick). The grey ground consists of chalk, lead white, some earth pigments, and fine carbon black [7]. The black underlayer was found to contain some chalk, gypsum, and a few aluminium (Al)-containing particles, in addition to the many splintery particles of charcoal black. Its composition is comparable to that of the black underlayer in the background [9]. The backscatter image also showed a few light grey amorphous clusters within the black underlayer, within which mainly $\mathrm{Pb}, \mathrm{K}$ and $\mathrm{S}$ (data not shown) were detected. This points to the presence of palmierite $\left(\mathrm{K}_{2} \mathrm{~Pb}\left(\mathrm{SO}_{4}\right)_{2}\right)$ : a common degradation product found in historical oil paintings [15, 28-30].

Similar to the blue paint layer in sample 41, SEM-EDX and $\mu$-FTIR-ATR detected characteristic bands showing that the thin blue surface layer is composed of mainly ultramarine (lazurite) and chalk, with minor additions of a fine lead white, and gypsum (Fig. 3e-m). The layer also contains very few particles of a translucent red pigment that shows a pink UV-induced fluorescence (Fig. 3c). Using EDX, $\mathrm{Al}, \mathrm{Ca}$ and $\mathrm{S}$ were co-detected; these are associated with a lake substrate, implying the use of a red organic lake on an $\mathrm{Al}$ substrate. The red lake was present in such a small quantity that it presumably had little effect on the eventual colour of the paint; other components (especially chalk) seemed to have a much larger impact on both optical and handling properties of the paint.

Macroscopic X-ray powder diffraction imaging (MAXRPD) in reflection mode detected calcium oxalates and imaged their distribution in the shadow zone of the blue headscarf [29]. Calcium oxalates, like palmierite, are common degradation products in oil paintings, and here seem related to the presence of chalk [31,32]. They may be held responsible for the whitish and patchy appearance of the shadow zone of the headscarf. The $\mu$-FTIRATR analyses of samples 41 and 42, however, were not able to detect any calcium oxalates at the surface or within the blue paint layers. Although $\mu$-FTIR-ATR is an effective method to identify calcium oxalates on paint fragments, the spatial resolution achieved here is limited to c. 4 to $6 \mu \mathrm{m}$. If the formation of calcium oxalates is a surface phenomenon, the layer of oxalates would be only c. $1 \mu \mathrm{m}$ thick in cross-section, and this is below the spatial resolution of the present $\mu$-FTIR-ATR instrument. It is also possible that the calcium oxalates formed in such low quantities that they could not be detected with $\mu$-FTIR-ATR.

Samples 41 and 42 are from neighbouring regions and both show similar compositions, yet each has a different build-up with respect to blue: one thick and the other thin. From the SEM-EDX and $\mu$-FTIR-ATR, it can be concluded from the relative abundance of bright blue particles of lazurite that Vermeer used a high-quality ultramarine.

\section{Synchrotron $\mu$-XANES of ultramarine pigment}

Using $\mu$-XANES, further information about the preparation of ultramarine pigment in samples 41 and 42 was determined: specifically, whether the lazurite was extracted from a heat-treated lapis lazuli rock. The location of lazurite particles in each sample was determined from $\mu$-XRF maps of $\mathrm{Si}, \mathrm{Al}$, and $\mathrm{S}$ (Fig. 4a), and several $\mu$-XANES spectra were then acquired across each lazurite particle. Figure $4 \mathrm{~b}$ presents a selection of averaged $\mu$-XANES spectra from lazurite particles within both samples (solid curves); the uppercase letters refer to the particles circled in Fig. 4a from which the spectral averages were taken. The general pattern of each matches that found in the literature for lazurite with a relatively low-intensity peak at $2469.0 \mathrm{eV}$, an 'envelope' of peaks between 2470.0 and $2475.6 \mathrm{eV}$, and a relatively highintensity peak at $2482.2 \mathrm{eV}$ [33-36]. With the exception of the peak at $2482.2 \mathrm{eV}$, which is attributed to sulphate, the peaks are reported as combined contributions from neutral, radical, and/or dianion sulphur species [33-37].

More closely, the relative ratio of peaks within the 'envelope' region-namely those at 2471.2, 2472.5, and $2473.8 \mathrm{eV}$-indicate the influence of heat-treatment [12]. It was recently found that for lazurite extracted from lapis lazuli heated at $600{ }^{\circ} \mathrm{C}$ the relative intensity of the peak at $2471.2 \mathrm{eV}$ was greater than that at 2472.5 and $2473.8 \mathrm{eV}$ In contrast, for lazurite from lapis lazuli left at room temperature or heated only at $415^{\circ} \mathrm{C}$, a local maximum was observed at $2472.5 \mathrm{eV}$. With further heating to $750{ }^{\circ} \mathrm{C}$, a clear minimum at $2472.5 \mathrm{eV}$ was also visible [12]. Using these criteria, conclusions may be drawn about the approximate temperature of treatment for the lapis lazuli rock from which the ultramarine in the headscarf of the Girl was extracted. Specifically, the 'envelope' region of spectra F, G, and H in Fig. 4b each shows a higher intensity at $2471.2 \mathrm{eV}$ relative to that at 2472.5 and $2473.8 \mathrm{eV}$, 

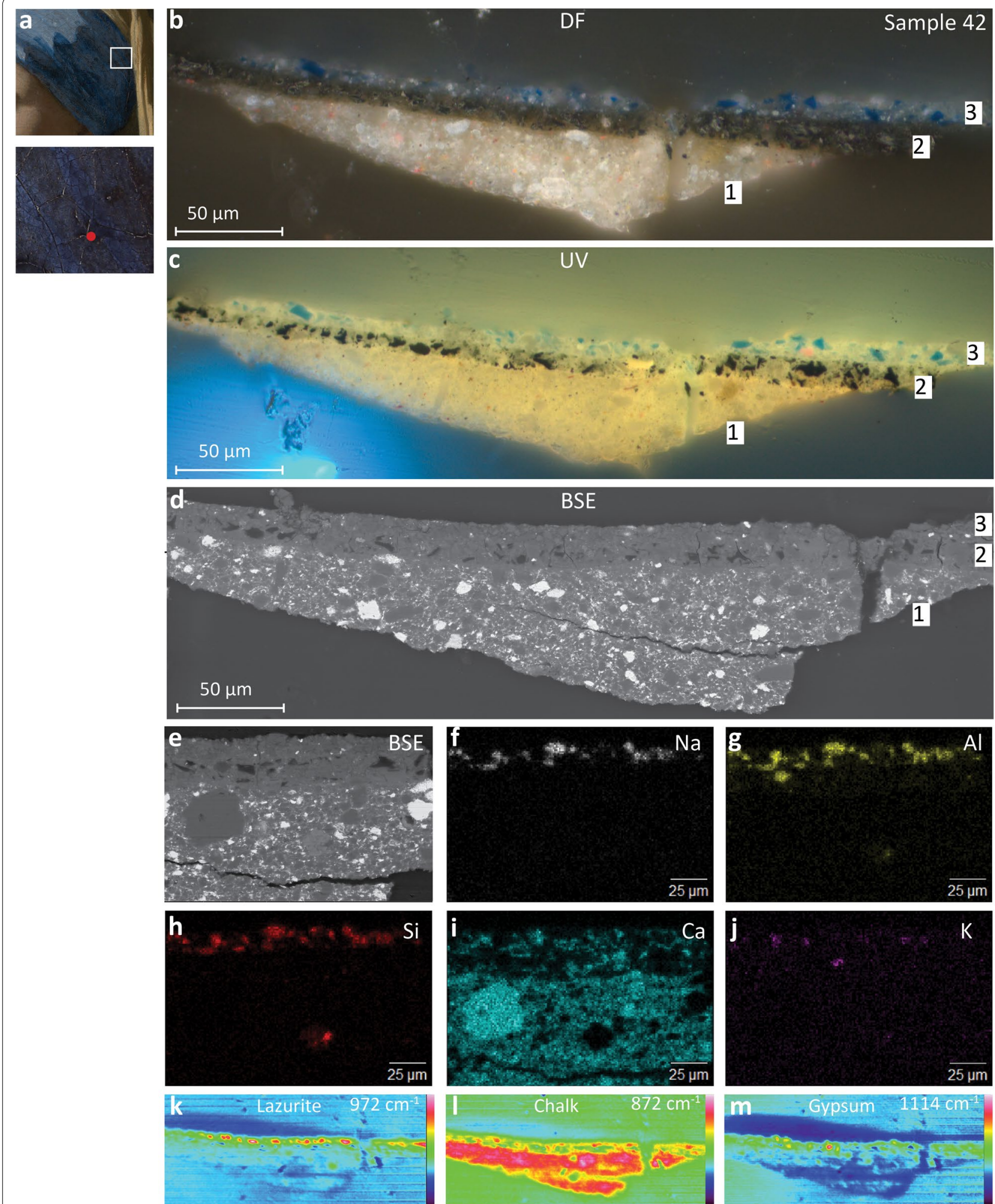

Fig. 3 Paint cross-section from a dark blue tone from right (shadow) side of blue headscarf (sample 42). a Sample location, b LM image, dark field, c UV-induced fluorescence. $\mathbf{d}$ Corresponding SEM backscattered-electron image. The sample was further polished for the data shown in $\mathbf{e}-\mathbf{m}$, and therefore do not correspond exactly to a-d. The EDX maps were done last. e detail SEM backscattered-electron image, EDX maps of: $\mathbf{f}$ sodium, $\mathbf{g}$ aluminium, $\mathbf{h}$ silicon, $\mathbf{i}$ calcium, $\mathbf{j}$ potassium. $\mu$-FTIR-ATR analysis: $\mathbf{k}$ distribution map of the $972 \mathrm{~cm}^{-1}$ band characteristic of lazurite, $\mathbf{I} 872 \mathrm{~cm}{ }^{-1}$ band characteristic of chalk, $\mathbf{m} 1114 \mathrm{~cm}^{-1}$ band characteristic of gypsum 

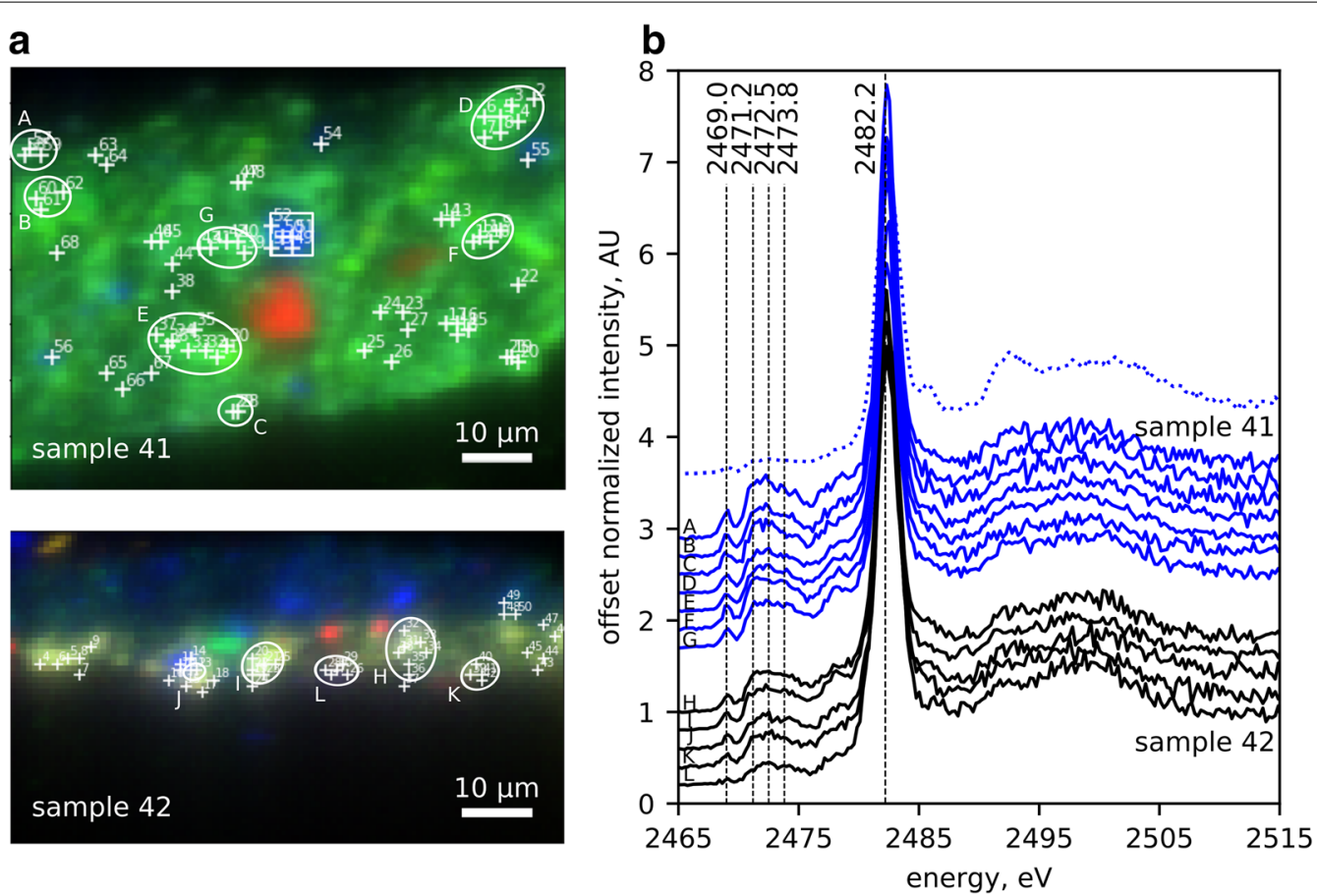

Fig. 4 Synchrotron $\mu$-XRF/ $\mu$-XANES of samples 41 and 42. a False-colour $\mu$-XRF maps of sample 41 (upper) and sample 42 (lower) used to select lazurite particles for $\mu$-XANES (attenuated) spectral acquisition from the co-location of silicon (red), aluminum (green), and sulphur (blue); numbers refer to individual spectral acquisitions. Particles circled in white and labelled with uppercase letters correspond to spectra (solid curves) plotted in b, each as the average over the individual scans acquired for a given particle. The particle boxed in white corresponds to the uppermost spectrum (dotted curve) in $\mathbf{b}$. $\mathbf{b}$ A selection of average normalised $\mu$-XANES (attenuated) spectra each from single particles in sample 41 (upper, blue curves) and sample 42 (lower, black curves); the selection was chosen based on signal-to-noise. The uppercase letters correspond to lazurite particles circled in a from which the averages were taken, ranging from two to eight spectra for each. The uppermost curve (dotted blue) corresponds to a particle of gypsum, boxed in a

yet no distinct minimum at $2472.5 \mathrm{eV}$. Such spectra correlate well with reference spectra of lazurite from lapis lazuli heated at $600{ }^{\circ} \mathrm{C}$ [12]. The remaining spectra of Fig. $4 \mathrm{~b}$ are intermediate between those from low temperature treatments and those of treatments at $600{ }^{\circ} \mathrm{C}$, indicative of the heterogeneity that arises with heat treatments [12]. Whether the heterogeneity is a result from mixing different batches of ultramarine pigments or from the partial conversion of species with heating cannot be determined. The similarity of the spectral shapes found in the two samples implies Vermeer used the same type of ultramarine for both applications; however, many more lazurite particles would need to be measured to determine this with certainty.

Finally, $\mu$-XANES also confirmed the presence of gypsum particles as revealed by $\mu$-FTIR-ATR. In sample 41 , $\mu$-XRF detected particles containing $S$ without a corresponding detection of $\mathrm{Al}$ and $\mathrm{Si}$ (Fig. 4a, upper, blue false-coloured particles). The $\mu$-XANES spectra from such particles-exemplified in Fig. 4b (uppermost curve, dotted blue)-present the characteristic spectral shape between c. 2482 and $2500 \mathrm{eV}$ for gypsum [38].

\section{Admixture of chalk or an organic lake pigment?}

The origin and effect of the large amount of chalk in samples from the shadow of the headscarf in Girl with a Pearl Earring remained partly unresolved. Some calcite is typically associated with the lazurite mineral. However, the amount of chalk present in the blue layers of samples 41 and 42 (c. 50 vol\%) can be considered too high to be only associated with ultramarine. It must come from another source. It could be an adulterant to bulk up the costly ultramarine, but the high quality of the pigment makes this unlikely. Another possibility is that extra chalk was added deliberately to the ultramarine glaze paint, to adjust its handling properties. A more likely possibility is that the chalk is present as a substrate of a-now fadedorganic lake pigment. The use of yellow lakes on a mainly chalk substrate has been reported in many genre paintings by Vermeer and his contemporaries, also in combination with ultramarine [3, 5]. In Vermeer's View of Delft (c. 1660-1661, Mauritshuis), the foliage containing ultramarine has a bluish appearance as a result of the fading of the yellow component, most likely a yellow lake on a chalk substrate [39]. 

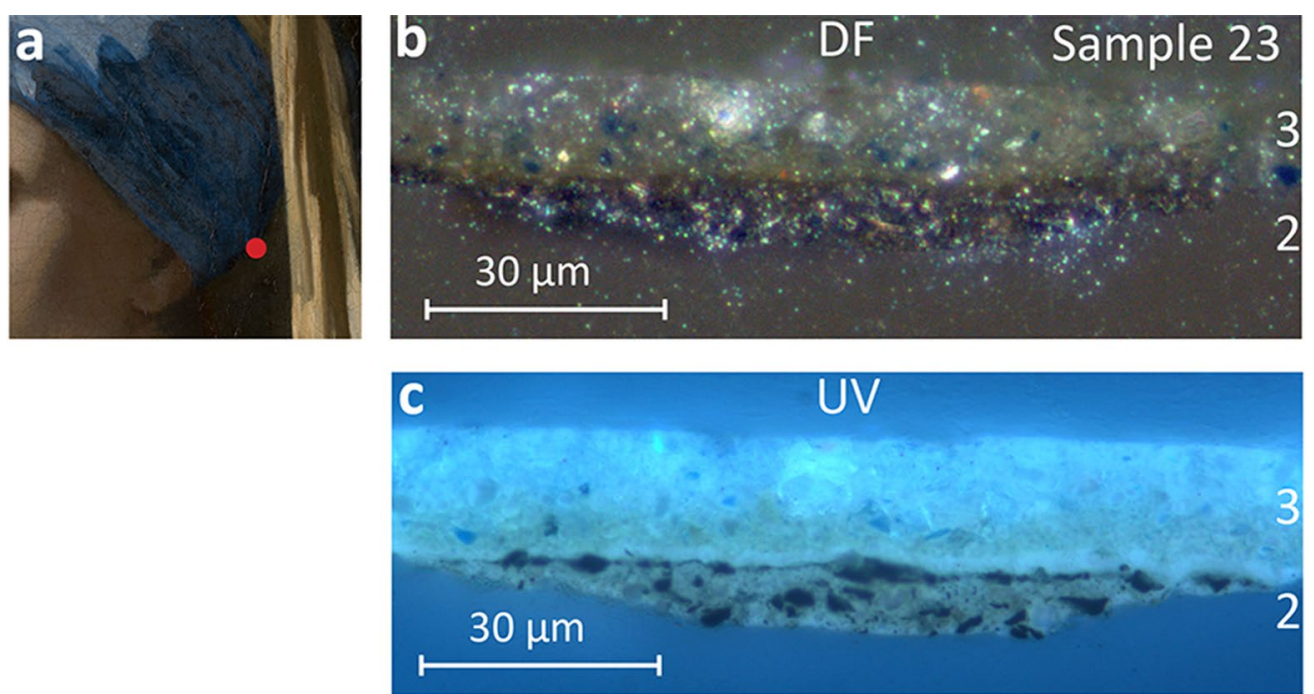

Fig. 5 Paint cross-section from lower right edge of the blue headscarf, at the transition with the dark background (sample 23). a Sample location, $\mathbf{b}$ LM image, dark field, c UV-induced fluorescence

In a cross-section, a gradient within a paint layer can be an indication that a yellow lake has faded: the upper part of the layer looks very pale, while the bottom part still exhibits some colour [40]. In Girl with a Pearl Earring, the chalk matrix surrounding the ultramarine particles in the ultra-thin blue layer of sample 42 is completely colourless (Fig. 3b, c). If it originally contained a lake, the dyestuff has now completely faded. The UV-induced fluorescence image of sample 41 showed a slightly stronger yellowish fluorescence at the bottom of the blue layer, but this was not convincing enough to conclude that a (yellow) lake was present (Fig. 2b, c). Unfortunately, there was not enough material from either of these samples to confirm the presence of an organic dyestuff using UHPLC analysis.

In an attempt to find more indication for the use of a lake, the use of lakes in other areas of the painting-the background and the Girl's jacket-was investigated as part of the current study. Sample 23 from the edge of the headscarf, adjacent to the dark background, clearly shows a gradient within the surface paint layer; the bottom part exhibits a yellowish UV-induced fluorescence, while the top part is much paler (Fig. 5b, c, layer 3. Table 1). It contains a relatively thick layer (c. $30 \mu \mathrm{m})$ with ultramarine and high amounts of chalk; the proportion of ultramarine to chalk estimated to be about 25:75 on the basis of the LM and SEM images (not shown). It appears that some glaze from the background of the painting (see below) was blended into this paint, showing fine blue particles of indigo at the top of the layer (instead of ultramarine). Analysis with UHPLC-PDA-FLR of two tiny unmounted fragments from the same location detected indigotin as the main organic colourant, as well as several unidentified yellowish components (spectra not shown). In the 1990s, Groen et al. [6] determined that the glaze in the background of the painting contained indigo and a yellow lake (weld) on a chalk substrate with minor traces of alum. The yellow component has completely faded over the entire background, except in a few restricted areas that had been covered with old retouchings, removed during the 1994 treatment [8]. As part of the Girl in the Spotlight research, two small paint fragments from the background glaze were analysed using UHPLC-PDAFLR, which confirmed the presence of luteolin (from weld) and indigotin (from indigo) in the glaze [9].

Although the Girl's jacket appears yellow where it faces the light, the paint also contains a small amount of ultramarine, mixed with lead white, yellow ochre and a tiny amount of red lake. The shadow of the jacket contains ultramarine, yellow ochre and a red lake pigment; hardly any chalk was detected [7]. Analysis with UHPLCPDA-FLR of a dislodged paint fragment from the jacket (sample 14a) detected carminic acid, and some other red fluorescent colourants,-such as dcIV, dcVII, kermesic acid and dc equivalents-implying the use of American cochineal (Dactylopius coccus Costa.) (spectra not shown). The co-detection of $\mathrm{Al}, \mathrm{K}$ and $\mathrm{S}$ in the red lake particles with EDX indicated that the red dyestuff has an alum substrate (spectra not shown).

In all occurrences of a red lake in Girl with a Pearl Earring, the substrate was alum $[7,15]$. In contrast, the yellow lake (weld) identified in the background glaze was precipitated or adsorbed on chalk with only minor traces of alum $[6,9]$. This further supports the hypothesis that 
the chalk found in the blue paint layers of the headscarf is the substrate of a-now faded-yellow lake, and not from a red lake. This is also in agreement with lake recipes from contemporary sources. The recipes for yellow lakes (schiet-yellow) typically contain more chalk than alum [41, 42]. Reconstructions of yellow lake recipes by Hermens and Wallert showed that the bulk of the material consisted of calcium carbonate white, with some calcium sulphate and some aluminium hydroxide [41]. Thus the presence of some calcium sulphate (gypsum) (identified with SEM-EDX and $\mu$-FTIR-ATR, Figs. 2, 3), evenly distributed within the blue paint layers of the Girl's headscarf, may also originate from a lake pigment. Paint reconstructions by Saunders and Kirby demonstrated that yellow lakes made with calcium-based substrates are most vulnerable to light-induced fading [43].

As part of the current study, schematic reconstructions were made to further investigate the visual and rheological effect of adding chalk or yellow lake to an ultramarine paint (Fig. $6 \mathrm{c}-\mathrm{j}$ ). An ultramarine paint was mixed with varying quantities $(0,25,50$ and 75 volume\%) of either chalk, or weld (Reseda luteola) precipitated onto a chalk/ alum substrate (weight proportions of chalk:alum 4:1). The methodology is described in Additional file 1. Pure ultramarine in oil was difficult to apply evenly, and making a long fine brushstroke required reloading the brush with paint (Fig. 6c). Adding chalk improved the handling properties significantly, and only a small amount was required (Fig. 6e); there was no noted improvement when a larger proportion (50-75\%) was added (Fig. 6g, i). Adding too much chalk negatively affected the appearance of the paint, making the glaze more opaque and 'cloudy'.

Reconstructions showed that adding yellow lake also improved the handling properties of an ultramarine paint. It was observed that a small amount (25\%) of yellow lake did not change the colour of the blue paint significantly (Fig. 6f); The 50:50 ratio of yellow lake:ultramarine produced a blue-green (Fig. 6h). Only the 75:25 yellow lake:ultramarine created a distinctively green colour (Fig. 6j). The effect of the addition of a yellow lake on the original appearance of the headscarf is discussed at the end of the next section.

\section{Painting process of the blue headscarf}

The results of complementary analyses using MS-IRR, MA-XRF, RIS-combined with micro-sample analysis and microscopic examination of the paint surface and high-resolution 3D digital microscopy-revealed the steps that Vermeer took to paint the different zones of the headscarf. The headscarf is visually divided into three distinct zones (Fig. 7a): the strongly lit part on the left (Fig. 7a, zone 1), a middle tone that is a slightly brighter blue (Fig. 7a, zone 2), and the shadow on the right (Fig. 7a, zone 3).

In the initial stages of the painting process, Vermeer prepared different parts of the composition with monochrome underlayers: in shades of cream, brown and black $[7,9,15]$. A black underlayer was restricted to the right side of the headscarf, which would eventually become the shadow (Fig. 7a, zone 3). MS-IRR (1900-2500 nm) showed that it was applied with broad horizontal brushstrokes above her ear, and continues towards the crown of the Girl's head (Fig. 7b) [7]. This underlayer corresponds to layer 2 in the cross-sections (Figs. 2, 3).

In the left (light) zone and middle zone (Fig. 7a, zones 1 and 2), microscopic examination of the paint surface showed that the light blue paint appears to have been applied directly onto the grey ground layer. The carbon black in the ground can cause a decrease in slope for NIR wavelengths as was observed with reflectance imaging [8]. 3D microphotographs reveal the grey colour of the ground beneath where the paint is thin, slightly translucent, and/or abraded (Fig. 1d).

MA-XRF maps for $\mathrm{Pb}$ (Fig. 7c-e) showed that the paint in the left (light) and middle zones contain a significant amount of lead white. RIS identified mixtures of lead white and ultramarine in different proportions, showing most lead white in the left (light) zone [8]. In the false-colour RIS image obtained at 750, 550 and $450 \mathrm{~nm}$ (Fig. 7h), this zone appears light blue. Here the light blue paint was left exposed at the surface to create the highlight on the left side (Fig. 7a, zone 1).

After the shadow and light zones had been established, Vermeer applied a thin blue layer-with little or no modelling-over the shadow, and partially extending over the middle section of the headscarf (this is layer 3 in sample 42, see Fig. 3). MA-XRF maps for $\mathrm{Pb}$ show that the paint in the shadow zone contains relatively low quantities of lead white (Fig. 7d, e). The thin blue paint application in the shadow zone was also visualised in the $\mathrm{Ca}$ and $\mathrm{K}$ maps (Fig. 7f, g). This is in agreement with sample 42 (Fig. 3, layer 3), in which ultramarine and chalk (presumably from a lake substrate) were detected in the thin blue paint. For the construction of the darkest blue shadows, Vermeer made deliberate use of the black underlayer to play a role in the final colour: he applied the final blue paint very thinly with respect to other layers, leaving the black underlayer partially exposed. This effective layer build-up is typical of Vermeer's painting technique [44].

In the next step, Vermeer defined the middle section (Fig. 7a, zone 2) of the headscarf with a blue paint: more intense in colour than the highlight on the left, but also containing lead white and (more) ultramarine. The colour of the paint is not entirely homogeneous: some brighter strokes were applied wet-in-wet to enliven the middle 


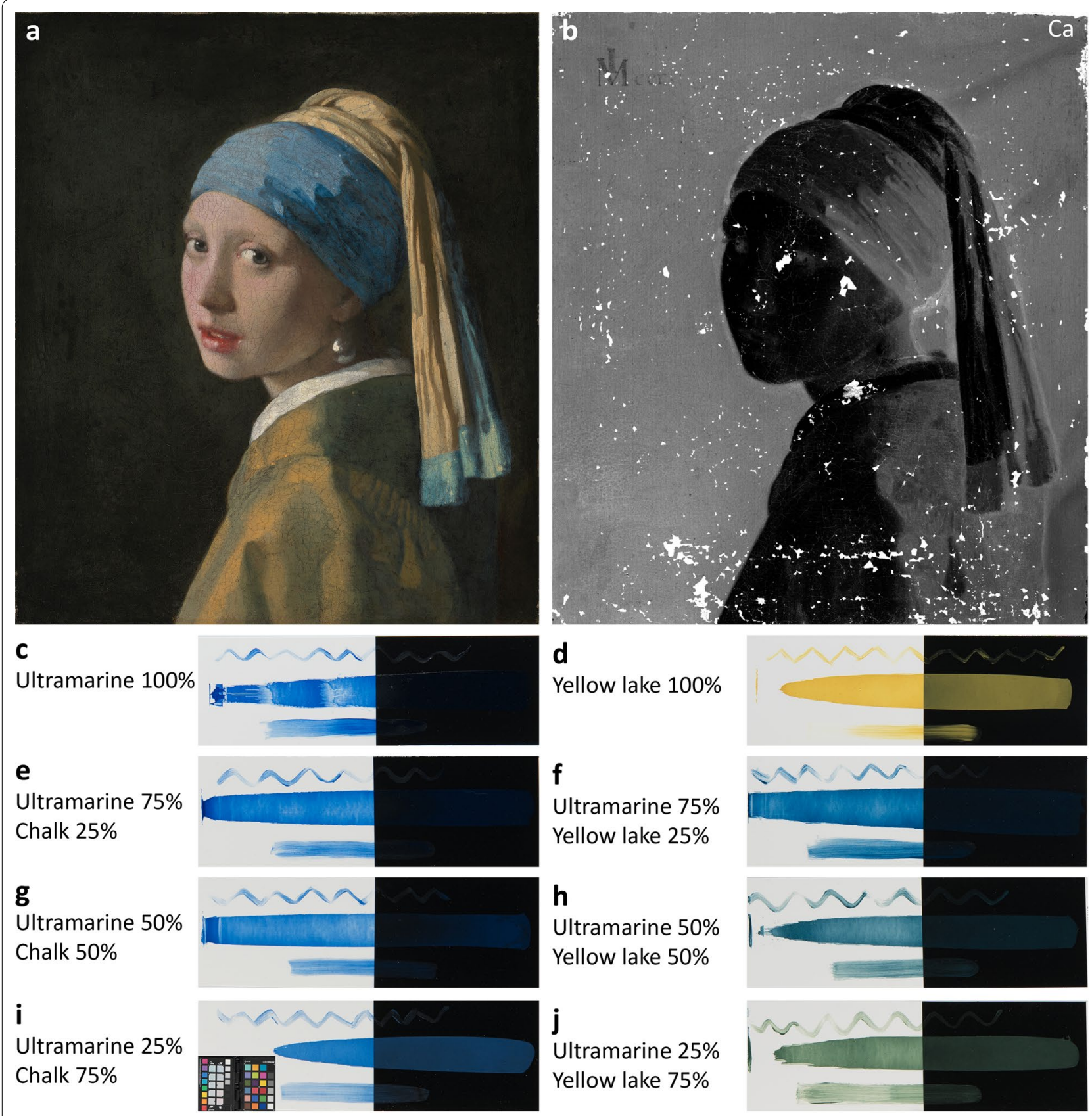

Fig. 6 a Visible light image. Photo credits: René Gerritsen Art \& Research Photography. b MA-XRF map of calcium. c-j Paint reconstructions with ultramarine (lapis lazuli, Kremer), chalk and yellow lake (weld on chalk/alum substrate) in different proportions (vol\%). The paints were applied with a paint applicator (50 and $100 \mu \mathrm{m}$ thick films; $100 \mu \mathrm{m}$ films shown in $\mathbf{c}-\mathbf{j}$ ) and a broad and fine brush onto black and white sealed opacity charts

zone. Vermeer applied the blue paint rather thickly on top of the light blue layer, using curved brushstrokes to create 'undulating' folds between the highlight and midtone (Fig. 1e), and between the midtone and shadow. He dragged the paint in fine lines towards the back of the headscarf to depict linear folds. The distribution of this layer is most clear in the false-colour RIS, where it appears light pink (Fig. 7h).

In the final stages, Vermeer applied an intensely coloured blue glaze to delineate the deepest folds in the scarf (this is layer 3 in sample 41, see Fig. 2). The glaze consists of mostly ultramarine and chalk (possibly from an organic lake, which has since faded). In the false-colour 

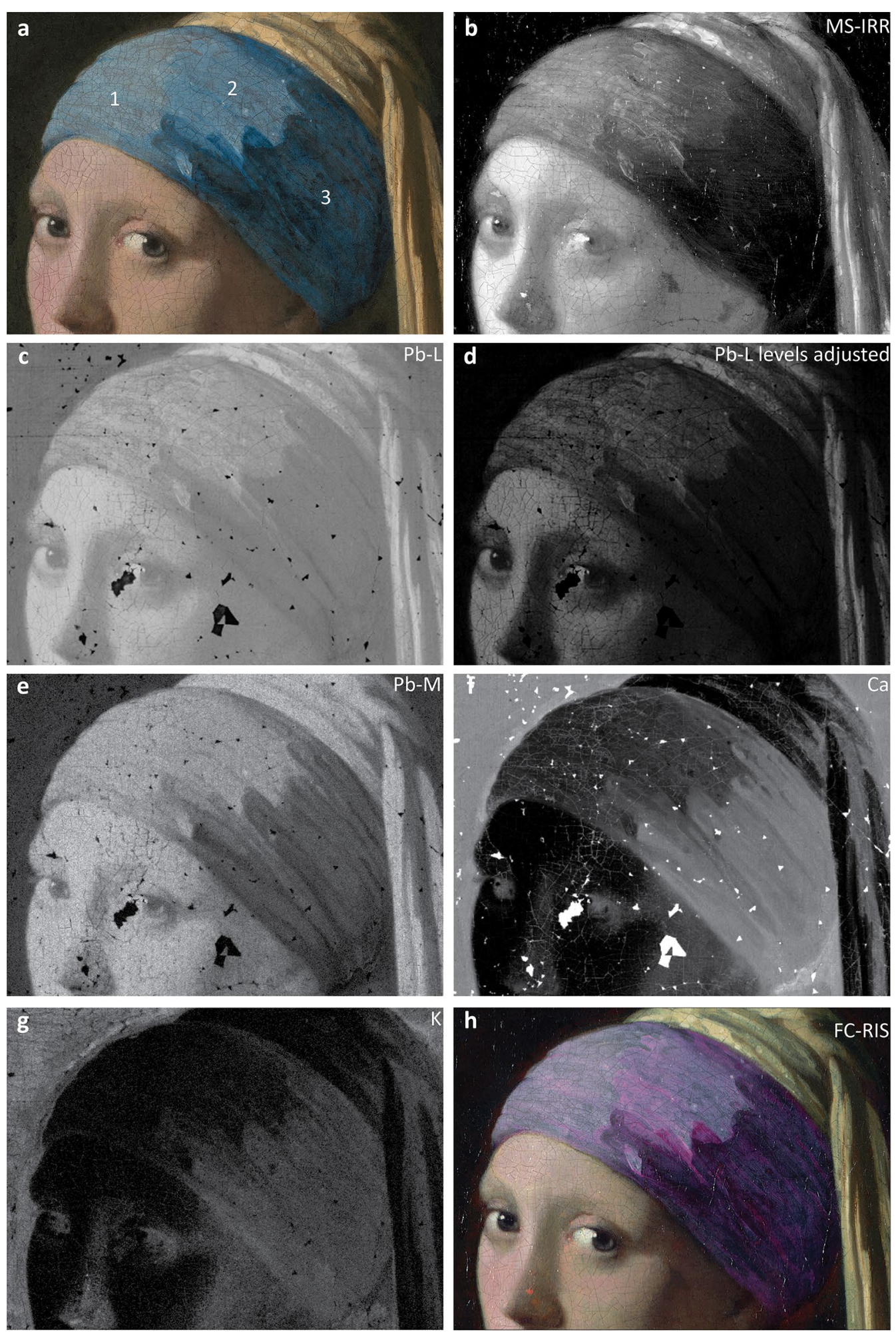

Fig. 7 Blue headscarf visualised with different non-invasive imaging methods. a Visible light image of blue headscarf showing three distinct zones: 1. highlight, 2. middle tone, 3. shadow, b MS-IRR infrared image (1900-2500 nm) [7], MA-XRF maps of: c-e lead, $\mathbf{f}$ calcium, $\mathbf{g}$ potassium, $\mathbf{h}$ RIS false colour image obtained at 750, 550, $450 \mathrm{~nm}$ [8] 
RIS image, the glaze appears as dark magenta (Fig. 7h). It shows that the glaze is mostly concentrated on the right side of the headscarf, but some brushstrokes extend slightly over the middle section. One wide brushstroke of blue glaze that overlaps the lighter blue layer counterbalances the undulating folds in the layer beneath (Fig. 1f). A thick glaze applied with a narrow brush created folds that extend towards the back of the Girl's head. While this intensely coloured glaze would have given depth to the shadow of the headscarf when it was first painted, it has since degraded (see sections above). For instance, a fold that is clearly visible as a magenta line above the Girl's ear in the false-colour RIS image is barely visible to the naked eye (Fig. 7a, h).

The blue paint layers in the headscarf were painted rather late in relation to the other colour areas within the painting. When the contours where different colours overlap with each other are examined under the stereomicroscope, it is clear that the blue paint layers of the headscarf were painted after (and partially on top of): the yellow part of the scarf, the (underlayer of the) background, and the skin tones.

The last touches that Vermeer applied are small dots on the surface of all three zones of the headscarf, which can be seen in the 3D digital micrographs [45]. Similar dots are found throughout the painting, including on her yellow jacket, and on the border of the yellow 'tail' of her headscarf. These dots create the illusion of texture without specifying a particular type of fabric; however, the subtle undulating way that Vermeer painted the folds in the fabric suggests a silky cloth.

Vermeer's sophisticated layering within the headscarf creates the illusion of a folded cloth strongly lit from one side. Unfortunately, the illusion has been somewhat compromised by degradation and fading. Although we cannot know with certainty what the function of the chalk was in dark blue areas in the Girl's headscarf, the reconstructions were helpful in developing a hypothesis (Fig. 6c-j). The headscarf of Girl with a Pearl Earring may originally have had a much richer variety of blue shades, ranging from a vivid light blue in the lit part (zone 1) to a dark greenish blue in the shadow (zone 3). Vermeer mixed ultramarine into different proportions of lead white for the light blues of the lit and middle zone of the headscarf (zones 1 and 2). He created the deepest blue-green shadows in the right (shadow) zone, making sophisticated use of the black underlayer; this effect is less visible now because of the whitish surface haze. Alternating wide and narrow brushstrokes of a greenish blue-now a patchy bright blue due to loss of the yellow component-were applied on top of the deep blue-green shadow zone to achieve modelling. The back contour of the headscarf above the Girl's neck was probably green.
The 'tail' at the back of the Girl's headscarf currently has a stark contrast between a light yellow (left) and a bluish shadow (right), with a yellow-green border at the bottom (Fig. 6a). RIS and MA-XRF showed that the highlights in the border contain both ultramarine and leadtin yellow, and do not appear discoloured [8]. The XRF map of Ca (Fig. 6b) suggests that Vermeer also mixed a yellow lake-now completely faded-into the blue (shadow) zone of the 'tail', which implies that it was once blue-green or green. The application of a deep blue-green or green glaze for the shadow area would also have better matched the yellow-green highlights at the border of the yellow headscarf.

\section{Conclusions}

The micro-analyses showed that Vermeer used a highquality ultramarine to paint the Girl's blue headscarf. Analysis using SEM-EDX and $\mu$-FTIR-ATR found only a few particles of accessory minerals relative to the number of lazurite particles. The $\mu$-XANES analysis of the lazurite particles suggests that Vermeer obtained his ultramarine pigment-at least in part-from a heat-treated rock. The combination of MS-IRR, MA-XRF, RIS, 3D digital microscopy, microscopic surface examination and sample analysis was crucial for understanding the pigment distributions. It also showed that Vermeer painted the headscarf in three distinct zones. The effective layering and wet-in-wet applications created the illusion of a folded cloth strongly lit from one side.

Investigating the material composition and recognising the paint degradation helped to comprehend the original appearance of the blue headscarf. Although we could not identify a yellow dye in the blue headscarf with certainty, it is very possible that the large amounts of chalk in the ultramarine paint are the substrate of a-now faded-yellow lake. Paint reconstructions with ultramarine mixed into different proportions of yellow lake helped to understand the original colour scheme. Using a limited number of pigments, Vermeer achieved a diverse palette of different shades of blue, yellow and green. The blue headscarf probably ranged from a light blue (zone 1) to a more intense blue (zone 2) to a deep dark blue/green (zone 3); the yellow 'tail' of the headscarf was mostly executed in yellow and green colours.

\section{Supplementary information}

Supplementary information accompanies this paper at https://doi. org/10.1186/s40494-020-00364-5.

Additional file 1. Painted reconstructions. 


\section{Abbreviations}

3D: 3-Dimensional; $\mu$-FTIR-ATR: Fourier transform infrared spectroscopyattenuated total reflectance spectroscopy; HPLC: High performance liquid chromatography; LED: Light emitting diode; LM: Light microscopy; MA-XRF: Macroscopic X-ray fluorescence imaging; MA-XRPD: Macroscopic X-ray powder diffraction imaging; MS-IRR: Multispectral infrared reflectography; RIS: Reflectance imaging spectroscopy; SEM-EDX: Scanning electron microscopyenergy dispersive X-ray analysis; SWIR: Shortwave infrared; UHPLC-PDA-FLR: Ultra-high-performance liquid chromatography with a photodiode array, attached to a fluorescence detector; UV: Ultraviolet; VNIR: Visible-to-nearinfrared; $\mu$-XANES: Micro X-ray absorption near-edge structure spectroscopy; $\mu$-XRF: Micro X-ray fluorescence spectroscopy.

\section{Acknowledgements}

The research project The Girl in the Spotlight is a Mauritshuis initiative, led by paintings conservator Abbie Vandivere, with a team of internationally recognised specialists working within the collaborative framework of the Netherlands Institute for Conservation + Art + Science + (NICAS). The authors would like to thank the following people for their useful discussions, and assistance with analysis and technical examination: René Gerritsen and Jaap Hoogerdijk, (René Gerritsen Art \& Research Photography); Ralph Haswell and Bob van Wingerden (Shell Technology Centre Amsterdam); Klaas Jan van den Berg (Cultural Heritage Agency of the Netherlands); Steven De Meyer, Frederik Vanmeert, Geert Van der Snickt, Koen Janssens (University of Antwerp); Joris Dik (Delft University of Technology); Lea van der Vinde (Mauritshuis). We are grateful to John Delaney and Kathryn A. Dooley (National Gallery of Art Washington) for providing the MS-IRR and RIS images, description of experimental methods, and for their valuable suggestions to the manuscript. For assisting with the reconstructions, the authors would like to acknowledge Fahed Ibrahim (student University of Amsterdam). XANES experiments were performed on beamline ID21 at the European Synchrotron Radiation Facility (ESRF), Grenoble, France (experiment HG139) for which the authors give thanks. The authors also thank Rob Erdmann (Rijksmuseum) for support in Python.

\section{Authors' contributions}

AvL acquired, processed and interpreted the MA-XRF data, performed the LM and SEM-EDX, evaluated the painting sequence and brushwork style, and carried out the schematic paint reconstructions. AV coordinated The Girl in the Spotlight project, and evaluated the painting sequence and brushwork style. AAG, VG, MC, WdN and KK acquired, processed and interpreted the XANES data. EL did the examination with the 3D digital microscope, and stitched the images. SdG performed the FTIR-ATR analysis. ANPG performed the UHPLCPDA-FLR analysis. AvL wrote the main body of the text. AV made significant contributions to the text. AAG wrote the section about the XANES. AAG, VG, MC, WdN and KK made valuable comments and suggestions to the text. All authors read and approved the final manuscript.

\section{Funding}

The Netherlands Institute for Conservation + Art + Science + funded the participation of the NICAS partners in the project, including the use of analytical equipment and the time devoted to the project by scientists from the RCE, TU Delft, University of Amsterdam and the Rijksmuseum. The Girl in the Spotlight project was made possible with support from the Johan Maurits Compagnie Foundation. AAG gives thanks to AkzoNobel for funding. MC thanks the KNAW for supporting her stays in The Netherlands through the Descartes Huygens prize.

\section{Availability of data and materials}

The datasets used and/or analysed during the current study are available from the corresponding author on reasonable request. The datasets supporting the conclusions of this article are included within the article and its additional files.

\section{Competing interests}

The authors declare that they have no competing interests.

\section{Author details}

${ }^{1}$ Conservation Department, Mauritshuis, Plein 29, 2511 CS The Hague, The Netherlands. ${ }^{2}$ Rijksmuseum Conservation \& Science, Ateliergebouw, Hobbemastraat 22, 1071 ZC Amsterdam, The Netherlands. ${ }^{3}$ Department of Materials Science and Engineering, Delft University of Technology, Mekelweg 2, 2628 CD Delft, The Netherlands. ${ }^{4}$ European Synchrotron Radiation Facility (ESRF),
71 Avenue des Martyrs, 38000 Grenoble, France. ${ }^{5}$ Sorbonne Université, CNRS, Laboratoire d'archeologie moleculaire et structurale, 4 place Jussieu, 75005 Paris, France. ${ }^{6}$ Van 't Hoff Institute for Molecular Sciences, University of Amsterdam, Science Park 904, 1098 XH Amsterdam, The Netherlands.

${ }^{7}$ Hirox Europe - Jyfel Corporation, 300 Route Nationale 6, Le bois des côtes, 69760 Limonest, France. ${ }^{8}$ Cultural Heritage Agency of the Netherlands (RCE), Hobbemastraat 22, 1071 ZC Amsterdam, The Netherlands.

\section{Received: 12 November 2019 Accepted: 9 February 2020}

Published online: 28 February 2020

\section{References}

1. Costaras N. A study of the materials and techniques of Johannes Vermeer. In: Gaskell, Jonker M, editors. Vermeer studies, studies in the History of Art 55. Washington/New Haven and London: National Gallery of Art/Yale University Press; 1998. p. 145-68.

2. Van Suchtelen A, Buvelot $Q$, Goverde M, Vandivere A, van der Vinde L, Buijsen E, Pottasch C, Meloni S. Genre paintings in the Mauritshuis. The Hague/Zwolle: Mauritshuis/Waanders Publishers; 2016.

3. Gifford EM, Glinsman LD. Collective style and personal manner: materials and techniques of high-life genre painting. In: Waiboer AE, Wheelock Jr. AK, Ducos B, Bakker P, Buvelot P. Vermeer and the masters of genre painting: Inspiration and rivalry. New Haven and London: Yale University Press, in association with the National Gallery of Ireland; 2017. p. 65-83.

4. Verslype I. The restoration of woman in blue reading a letter by Johannes Vermeer. The Rijksmuseum Bulletin. 2012;60(1):2-19. https://www.jstor .org/stable/41703552.

5. Vermeer's palette. Vermeer and technique [Internet]. 2013. https://www. nationalgallery.org.uk/paintings/research/meaning-of-making/verme er-and-technique/vermeers-palette. Accessed 29 Aug 2019.

6. Groen K, van der Werf I, van den Berg K, Boon J. Scientific examination of Vermeer's "Girl with a Pearl Earring". In: Gaskell I, Jonker M, editors. Vermeer studies, studies in the History of Art 55. Washington/New Haven and London: National Gallery of Art/Yale University Press; 1998. p. 169-84.

7. Vandivere A, van Loon A, Dooley KA, Haswell R, Erdmann RG, Leonhardt E, Delaney JK. Revealing the painterly technique beneath the surface of Vermeer's Girl with a Pearl Earring using macro- and microscale imaging. Herit Sci. 2019;7:64. https://doi.org/10.1186/s40494-019-0308-4.

8. Delaney JK, Dooley KA, Van Loon A, Vandivere A. Mapping the pigment distribution of Vermeer's Girl with a Pearl Earring. Herit Sci. 2020;8:4. https ://doi.org/10.1186/s40494-019-0348-9.

9. Vandivere A, van Loon A, Callewaert T, Haswell R, Proaño Gaibor AN, van Keulen $\mathrm{H}$, Leonhardt E, Dik J. Fading into the background: the dark space surrounding Vermeer's Girl with a Pearl Earring. Herit Sci. 2019;7:69. https ://doi.org/10.1186/s40494-019-0311-9.

10. Van Peer AJJM. Drie collecties schilderijen van Jan Vermeer. Oud Holland. 1957;72:92-103. https://www.jstor.org/stable/42718101.

11. Vandivere A, Wadum J, van den Berg KJ, van Loon A. From 'Vermeer Illuminated' to 'The Girl in the Spotlight': approaches and methodologies for the scientific (re-) examination of Vermeer's Girl with a Pearl Earring. Herit Sci. 2019;7:66. https://doi.org/10.1186/s40494-019-0307-5.

12. Gambardella AA, Cotte M, de NolfW, Schnetz K, Erdmann R, van Elsas R, Gonzalez V, Wallert A, ledema P, Eveno M, Keune K. Sulfur K-edge micro- and full-field XANES identifies marker for preparation method of ultramarine pigment from lapis lazuli in historical paints. Sci Adv. 2020; (in press).

13. Alfeld M, Janssens K, Dik J, de Nolf W, Van der Snickt G. Optimization of mobile scanning macro-XRF systems for the in situ investigation of historical paintings. J Anal At Spectrom. 2011;26(5):899-909. https://doi. org/10.1039/c0ja00257g.

14. Klaas, J. Die "Ultramarinkrankheit" Studien Zu Veränderungen in Ultramarinhaltigen Farbschichten an Gemälden. PhD dissertation. Munich: Technical University of Munich; 2011.

15. Van Loon A, Vandivere A, Delaney J, Dooley K, De Meyer S, Vanmeert F, Janssens K, Gonzalez V, Leonhardt E, Haswell R, de Groot S, Proaño Gaibor AN, D'Imporzano P, Davies GR. Beauty is skin deep: the skin tones of Vermeer's Girl with a Pearl Earring. Herit Sci. 2019;7:102. https://doi. org/10.1186/s40494-019-0344-0. 
16. De Keyser N, Van der Snickt G, van Loon A, Legrand S, Wallert A, Janssens K. Jan Davidsz. de Heem (1606-1684): a technical examination of fruit and flower still lifes combining MA-XRF scanning, cross-section analysis and technical historical sources. Herit Sci. 2016;5:38. https://doi. org/10.1186/s40494-017-0151-4

17. Noble P, van Loon A, Van der Snickt G, Janssens K, Alfeld M, Dik J. The development of new imaging techniques for the study and interpretation of late Rembrandt paintings. In: Preprints ICOM Committee for Conservation 17th Triennial Meeting, Melbourne, 15-19 September 2014

18. Vagnini M, Miliani C, Cartechini L, Rocchi P, Brunetti B, Sgamellotti A. FTNIR spectroscopy for non-invasive identification of natural polymers and resins in easel paintings. Anal Bioanal Chem. 2009;395:2107-18.

19. Plesters J. Ultramarine blue, natural and artificial. In: Roy A, editor. Artists' pigments, a handbook of their history and characteristics, vol. 2. Washington/New York: National Gallery of Art/Oxford University Press; 1993. p. 37-66.

20. Merrifield MP. Original treatises dating from the XIIth to XVIIIth centuries on the arts of painting. London: John Murray; 1849.

21. Van Loon A, Keune K, Boon JJ. Improving the surface quality of paint cross-sections for imaging analytical studies with specular reflection FTIR and static-SIMS. In: Proceedings of Art'05, conference on nondestructive testing and microanalysis for the diagnostics and conservation of the cultural and environmental heritage, Lecce, 15-19 May 2005.

22. Serrano A, van Bommel MR, Hallett J. Evaluation between ultrahigh pressure liquid chromatography and high-performance liquid chromatography analytical methods for characterizing natural dyestuffs. J Chromatogr A. 2013;1318:102-11. https://doi.org/10.1016/j.chroma.2013.09.062.

23. Conover DM, Delaney JK, Loew MH. Automatic registration and mosaicking of technical images of old master paintings. Appl Phys A. 2015;119(4):1567-75. https://doi.org/10.1007/s00339-015-9140-1.

24. Alfeld M, Vaz Pedroso J, Van Eikema Hommes M, Van der Snickt G, Tauber G, Blaas J, Haschke M, Erler K, Dik J, Janssens K. A mobile instrument for in situ scanning macro-XRF investigation of historical paintings. J Anal At Spectrom. 2013;28(5):760-7. https://doi.org/10.1039/c3ja30341a.

25. Alfeld M, Janssens K. Strategies for processing mega-pixel X-ray fluorescence hyperspectral data: a case study on a version of Caravaggio's painting Supper at Emmaus. J Anal At Spectrom. 2015;30(3):777-89. https ://doi.org/10.1039/c4ja00387j.

26. Delaney JK, Thoury M, Zeibel JG, Ricciardi P, Morales KM, Dooley KA. Visible and infrared imaging spectroscopy of paintings and improved reflectography. Herit Sci. 2016;4:6. https://doi.org/10.1186/s40494-016-0075-4.

27. Derrick MR, Stulik D, Landry JM. Infrared spectroscopy in conservation science. Los Angeles: The Getty Conservation Institute; 1999.

28. Van Loon A, Noble P, Boon J. White hazes and surface crusts in Rembrandt's Homer and related paintings. In: Bridgland J, editor. Preprints ICOM Committee for Conservation 16th Triennial Meeting, Lisbon, 19-23 September 2011. Almada: Critério - Produção Gráfica Lda.

29. De Meyer S, Vanmeert F, Vertongen R, van Loon A, Gonzalez V, Dik J, Van der Snickt G, Vandivere A, Janssens K. Imaging secondary reaction products at the surface of Vermeer's Girl with a Pearl Earring by means of in situ macro X-ray powder diffraction scanning. Herit Sci. 2019;7:67. https://doi. org/10.1186/s40494-019-0309-3.

30. Price SWT, van Loon A, Keune K, Parsons AD, Murray C, Beale AM, Mosselmans JFW. Unravelling the spatial dependency of the complex solid-state chemistry of $\mathrm{Pb}$ in a paint micro-sample from Rembrandt's Homer using XRD-CT. Chem Commun. 2019;55(13):1931-4. https://doi. org/10.1039/c8cc09705d.

31. Cariati F, Rampazzi L, Toniolo L, Pozzi A. Calcium oxalate films on stone surfaces: experimental assessment of the chemical formation. Stud Conserv. 2000:45(3):180-8.
32. Van Loon A. White hazes and surface crusts on dark oil paint films. In: Color changes and chemical reactivity in seventeenth-century oil paintings, PhD dissertation University of Amsterdam, Molart Series (14), AMOLF, Amsterdam. 2008. p. 206-39. http://www.amolf.nl/publications.

33. Goettlicher J, Kotelnikov A, Suk N, Kovalski A, Vitova T, Steininger R. Sulfur $\mathrm{KX}$-ray absorption near edge structure spectroscopy on the photochrome sodalite variety hackmanite. Z Krist. 2013;228:157-71. https:// doi.org/10.1524/zkri.2012.1587.

34. Fleet ME, Liu X. X-ray absorption spectroscopy of ultramarine pigments: a new analytical method for the polysulfide radical anion S3-chromophore. Spectrochim Acta B. 2010;65:75-9. https://doi.org/10.1016/j. sab.2009.11.008.

35. Gambardella AA, Schmidt Patterson CM, Webb SM, Walton MS. Sulfur K-edge XANES of lazurite: toward determining the provenance of lapis lazuli. Microchem J. 2016;125:299-307. https://doi.org/10.1016/j.micro c.2015.11.030.

36. Pascal TA, Pemmaraju CD, Prendergast D. X-ray spectroscopy as a probe for lithium polysulfide radicals. Phys Chem Chem Phys. 2015;17:7743-53. https://doi.org/10.1039/c4cp05316h.

37. Tauson VL, Goettlicher J, Sapozhnikov AN, Mangold S, Lustenberg EE. Sulphur speciation in lazurite-type minerals ( $\mathrm{Na}$, Ca)8[Al6Si6O24](SO4, S)2 and their annealing products: a comparative XPS and XAS Study. Eur J Mineral. 2012;24:133-52. https://doi. org/10.1127/0935-1221/2011/0023-2132.

38. Scheinost A. Gypsum. [Internet] https://www.esrf.eu/files/live/sites/ www/files/UsersAndScience/Experiments/XNP/ID21/php/gypsum/ gypsum.pdf. Accessed 29 Jan 2020.

39. Van Loon A. De korrelige verf in Vermeers Gezicht op Delft, nieuwe onderzoeksgegevens. kM Materiaaltechnische informatie over kunst en vormgeving. 2009;72:10-3.

40. Spring M. Pigments and color change in the paintings of Aelbert Cuyp. In: Wheelock Jr AK, editor. Aelbert Cuyp. Washington: National Gallery of Art; 2001. p. 64-73.

41. Hermens E, Wallert A. The Pekstok papers, lake pigments, prisons and paint-mills. In: Hermens E, Ouwerkerk A, Costaras N, editors. Looking through paintings, Leids Kunsthistorisch Jaarboek XI. London: Archetype; 1998. p. 269-94. [p. 274 Complexation of organic colours, with note 5 on p. 292].

42. Van de Graaf JA. Het Mayerne manuscript als bron voor de schildertechniek van de barok. PhD dissertation, University of Utrecht. Mijdrecht; 1958. p. 49, 151 (De Mayerne recipe 32).

43. Saunders D, Kirby J. Light-induced color changes in red and yellow lake pigments. Natl Gallery Tech Bull. 1994;15:79-97. https://www.nationalga llery.org.uk/technical-bulletin/saunders_kirby1994.

44. Gifford EM. Painting light: recent observations on Vermeer's technique. In: Gaskell I, Jonker M, editors. Vermeer studies, studies in the History of Art 55. Washington/New Haven and London: National Gallery of Art/Yale University Press; 1998. p. 185-200.

45. Vandivere A, Wadum J, Leonhardt E. The Girl in the Spotlight: Vermeer at work, his materials and techniques in Girl with a Pearl Earring. Herit Sci. 2020. https://doi.org/10.1186/s40494-020-0359-6.

\section{Publisher's Note}

Springer Nature remains neutral with regard to jurisdictional claims in published maps and institutional affiliations. 